BMJ Nutrition,

Prevention \& Health

\title{
Alcohol consumption and fruits and vegetable intake among older adults in Ghana: a cross-sectional survey based on WHO-SAGE Wave 2 data
}

\author{
Kenneth Tachi, ${ }^{1}$ John Tetteh, ${ }^{2}$ Alfred Edwin Yawson, ${ }^{2}$ Adwoa Agyei-Nkansah, ${ }^{1}$ \\ Timothy Archampong ${ }^{1}$
}

\begin{abstract}
To cite: Tachi K, Tetteh J, Yawson AE, et al. Alcohol consumption and fruits and vegetable intake among older adults in Ghana: a crosssectional survey based on WHO-SAGE Wave 2 data. BMJ Nutrition, Prevention \& Health 2020;3:e000102. doi:10.1136/ bmjnph-2020-000102

${ }^{1}$ Department of Medicine and Therapeutics, College of Health Sciences, University of Ghana Medical School, Korle Bu, Greater Accra, Ghana ${ }^{2}$ Department of Community Health, College of Health Sciences, University of Ghana Medical School, Korle Bu, Greater Accra, Ghana
\end{abstract}

Correspondence to Dr Kenneth Tachi, Department of Medicine and Therapeutics, University of Ghana College of Health Sciences, Accra, Greater Accra, Ghana; kennethtachi@yahoo.com

Received 10 May 2020 Revised 2 August 2020 Accepted 3 August 2020 Published Online First 21 September 2020

Check for updates

(c) Author(s) (or their employer(s)) 2020. Re-use permitted under CC BY-NC. No commercial re-use. See rights and permissions. Published by BMJ.

\begin{abstract}
Background Alcohol consumption and inadequate fruits and vegetable (FnV) intake are major reasons for the shift from communicable to non-communicable diseases (NCDs) over the years. The older Ghanaian adult is at high risk of NCD and data on alcohol and FnV consumption are required to guide policy to mitigate its effect. This analysis aimed to determine the factors associated with alcohol consumption and assess the relationship between alcohol consumption and FnV intake among Ghanaians aged 50 years and older.
\end{abstract}

Methods This analysis used WHO Study on Global Ageing and Adult Health (SAGE) Wave 2, Ghana data set conducted between 2014 and 2015. Data on demographic characteristics, FnV intake, and alcohol consumption were collated and analysed. Multivariable Poisson, logistic and probit regression analyses were performed to assess the associations between alcohol consumption and inadequate FnV intake.

Results A total of 3533 Ghanaians aged 50 years and older, $41.0 \%$ men and $59.0 \%$ women, were included in this study. The prevalence of lifetime alcohol consumption was $22.8 \%$ (95\% $\mathrm{Cl} 20.7 \%$ to $25.1 \%)$. Alcohol consumption was significantly associated with sex, age group, marital status, religion, place of residence and history of smoking. The prevalence of adequate $\mathrm{FnV}$ intake was $52.6 \%$ with a mean daily intake of 6.45 servings: 2.98 for fruits and 3.47 for vegetables. There was a significant positive correlation between inadequate $\mathrm{FnV}$ intake and alcohol consumption. Inadequate $\mathrm{FnV}$ consumption was significantly higher among lifetime alcohol consumers compared with nonalcohol consumers. (Poisson estimate; adjusted Prevalence Ratio (aPR) $(95 \% \mathrm{Cl})=1.35$ (1.12 to 1.63), logistic estimate; adjusted Old Ratio (aOR) $(95 \% \mathrm{Cl})=1.13$ (1.05 to 1.21$)$ and probit estimate; adjusted normalized coefficient (aß) $(95 \%$ $\mathrm{Cl})=0.19(0.07$ to 0.31$))$

Conclusion About a quarter and nearly half of older Ghanaian adults consume alcohol and inadequate $\mathrm{FnV}$, respectively. Alcohol consumption is significantly associated with inadequate $\mathrm{FnV}$ intake. Interventions to address inadequate FnV intake among older adults in Ghana should also include policies that regulate the use of alcohol in this population.
What this paper adds

- The prevalence of lifetime alcohol consumption among older adults is similar to that previously reported among secondary school stuents in Ghana

- The prevalecne of inadeqaute FnV is high among older adults in Ghana

- Alcohol comsumption is significantly associated with inadequate FnV intake amog older adults in Ghana

\section{INTRODUCTION}

Changes in dietary patterns including fruits and vegetable $(\mathrm{FnV})$ intake and alcohol consumption are considered the major reasons for the shift in disease pattern from communicable to non-communicable diseases (NCDs) observed between 1990 and 2010. ${ }^{1}$ FnV are essential ingredients of a healthy diet because they are rich sources of dietary fibre, vitamins, minerals, flavonoids and antioxidants necessary for good health. While the recommendation on adequate levels of $\mathrm{FnV}$ intake to obtain health benefits is still variable among countries, many experts and the $\mathrm{WHO}$ agree on a minimum intake of $400 \mathrm{~g} /$ day (five servings). ${ }^{2}$ A high intake of $\mathrm{FnV}$ diet has been associated with reduced risk of many NCDs including coronary heart diseases, colorectal cancers and strokes. ${ }^{2}{ }^{3}$ Unfortunately, inadequate $\mathrm{FnV}$ intake continues to be a contributor to the global rise in the burden of NCD. Worldwide, low intake of $\mathrm{FnV}$ is estimated to contribute to about $19 \%$ of gastrointestinal cancers, about $31 \%$ of ischaemic heart diseases and $11 \%$ of strokes. ${ }^{2}$ It also remains among the top 10 risk factors for global mortality. According to estimates by Lock et al, about 2.6 million deaths could be prevented annually by simply increasing FnV intake. ${ }^{4}$

The prevalence of inadequate $\mathrm{FnV}$ consumption varies globally. In a survey of 52 
Table 1 Descriptive prevalence of demographic characteristics associated with alcohol consumption among the older adults in Ghana

\begin{tabular}{|c|c|c|c|c|}
\hline \multirow[b]{2}{*}{ Demographic variable } & \multirow[b]{2}{*}{ Total } & \multicolumn{2}{|l|}{ Alcohol use } & \multirow[b]{2}{*}{$\chi^{2} \mathrm{P}$ value } \\
\hline & & No=77.2 (74.9-79.3) & Yes=22.8 (20.7-25.1) & \\
\hline & $\mathrm{n}$ & Weighted \% & Weighted \% & \\
\hline Sex & & & & $113.45(0.000)$ \\
\hline Male & 1455 & 63.3 & 36.7 & \\
\hline Female & 2078 & 89.2 & 10.8 & \\
\hline \multicolumn{5}{|l|}{ Age } \\
\hline Mean age (+SD) & $62.6(10.2)$ & $62.9(10.6)$ & $61.7(8.9)$ & $8.50(0.004)$ \\
\hline \multicolumn{5}{|l|}{ Age group, years } \\
\hline $50-59$ & 1275 & 75.1 & 24.9 & $3.48(0.019)$ \\
\hline $60-69$ & 1093 & 77.4 & 22.6 & \\
\hline $70-79$ & 764 & 80.5 & 19.5 & \\
\hline $80+$ & 401 & 82.5 & 17.5 & \\
\hline Marital status & & & & $12.23(0.000)$ \\
\hline Never married & 114 & 70 & 30 & \\
\hline Married & 1976 & 74.3 & 25.7 & \\
\hline Separated & 420 & 72.5 & 27.5 & \\
\hline Widowed & 1023 & 88.2 & 11.8 & \\
\hline Religion & & & & $45.39(0.000)$ \\
\hline None & 114 & 42.5 & 57.5 & \\
\hline Christian & 2545 & 75.1 & 24.9 & \\
\hline Islam & 657 & 95.1 & 4.9 & \\
\hline Prima indigenous & 217 & 65.8 & 34.2 & \\
\hline Place of residence & & & & $5.00(0.026)$ \\
\hline Urban & 1377 & 79.7 & 20.3 & \\
\hline Rural & 2156 & 74.8 & 25.2 & \\
\hline Region & & & & $5.69(0.000)$ \\
\hline Ashanti & 575 & 83.8 & 16.2 & \\
\hline Brong Ahafo & 376 & 81.3 & 18.7 & \\
\hline Central & 457 & 73.2 & 26.8 & \\
\hline Eastern & 284 & 70.7 & 29.3 & \\
\hline Greater Accra & 333 & 74.1 & 25.9 & \\
\hline Northern & 357 & 90 & 10 & \\
\hline Upper East & 191 & 83.4 & 16.6 & \\
\hline Upper West & 184 & 83.5 & 16.5 & \\
\hline Volta & 328 & 61.9 & 38.1 & \\
\hline Western & 448 & 78.8 & 21.2 & \\
\hline History of smoking & & & & $72.42(0.000)$ \\
\hline Yes & 247 & 42.1 & 57.9 & \\
\hline No & 3266 & 80.2 & 19.8 & \\
\hline \multicolumn{5}{|l|}{ BMI } \\
\hline Mean BMI (+SD) & $24.2(5.6)$ & $24.4(5.4)$ & $23.7(5.9)$ & $1.38(0.242)$ \\
\hline \multicolumn{5}{|l|}{ BMI category } \\
\hline Underweight & 427 & 71.1 & 28.9 & $2.49(0.067)$ \\
\hline Normal & 1844 & 75.3 & 24.7 & \\
\hline
\end{tabular}


Table 1 Continued

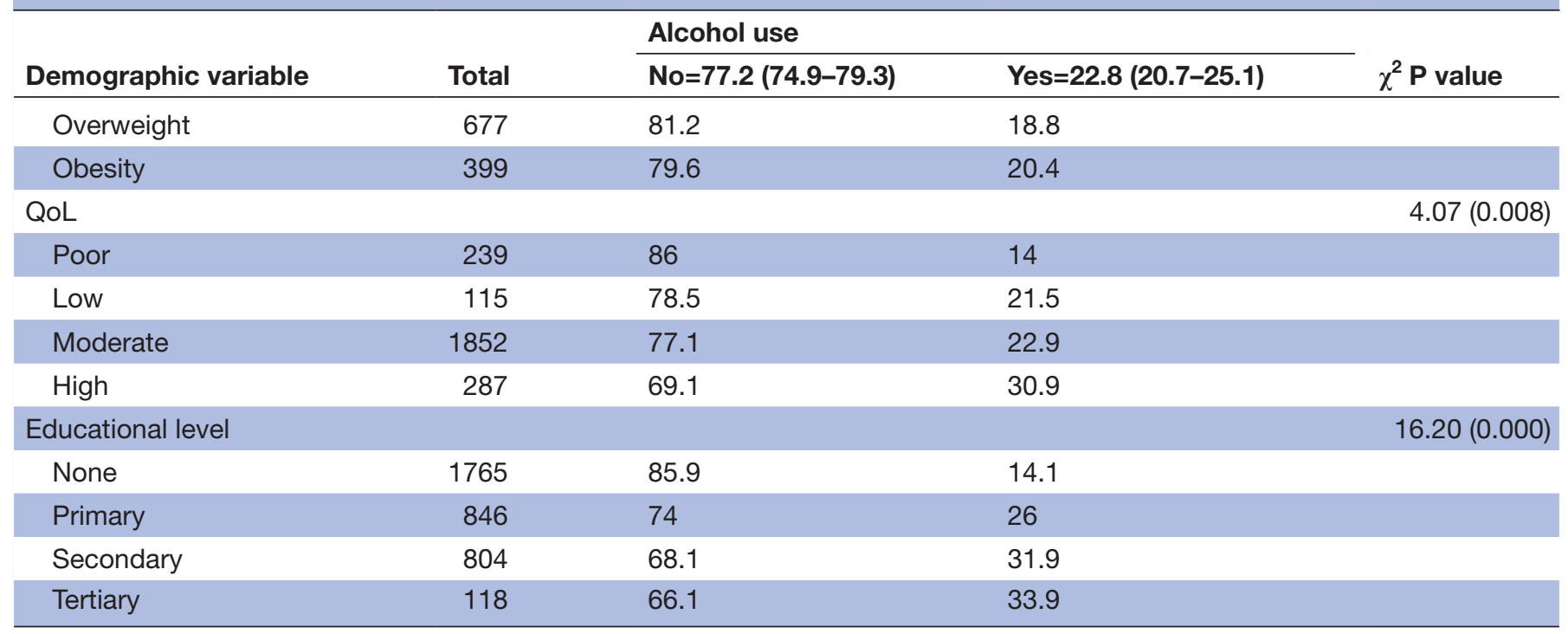

BMI, body mass index; QoL, quality of life.

countries by Hall et al, the prevalence of low FnV consumption ranged from $36.6 \%$ (Ghana) to $99.2 \%$ (Pakistan) for men and from $38.0 \%$ (Ghana) to $99.3 \%$ (Pakistan) for women. ${ }^{5} \mathrm{~A}$ similar trend was also reported by Wu et al in their evaluation of common risk factors for chronic NCDs during the Study on Global Ageing and Adult Health (SAGE) Wave 1 involving five countries. ${ }^{6}$ The reasons for inadequate intake of $\mathrm{FnV}$ are related to socioeconomic factors, such as income levels, marital status, age and educational attainment, and to health behaviours such as physical inactivity and smoking. ${ }^{78}$ Alcohol consumption is also recognised as one of the reasons for $\mathrm{FnV}$ consumption. ${ }^{9}$

In many societies today, alcohol consumption is a routine part of social life. According to the WHO, some 2.3 billion people are current drinkers who consume on average $32.8 \mathrm{~g}$ of pure alcohol per day. ${ }^{10}$ This is estimated to be even higher in the African region by some $20 \%$ $(40.0 \mathrm{~g} /$ day $) .{ }^{10}$ Compared with other regions, the WHO African region also has one of the worse alcohol-related health outcomes. ${ }^{10}$ The differences in the harmful effect of alcohol intake may partly be due to differences in the pattern of consumption including volume, frequency and type of alcoholic beverage consumed. ${ }^{11}{ }^{12}$ However, it may also be partly attributable to differences in the effect of alcohol on FnV intake.

Inadequate $\mathrm{FnV}$ intake and alcohol consumption have a direct association with NCDs. An inverse relationship, however, exits between these two lifestyles, alcohol consumption and FnV intake. Shimotsu et al reported that adults who consumed five or more servings of $\mathrm{FnV}$ per day were less likely to engage in binge drinking relative to those consuming zero to one serving of FnV per day. This finding was more so for adults with lower household incomes suggesting a role for economic status. ${ }^{13} \mathrm{~A}$ study in Laos, a lower-middle-income country reported past month binge drinking decreased the odds of having even three or more servings of vegetables daily. ${ }^{14}$ It is also likely that this relationship extends beyond the socioeconomically lowly placed in society. In a study of 72904 French women, FnV consumption was similarly negatively correlated with alcohol consumption..$^{15}$ Also, in Northern Italy, the mean number of portions of fresh fruit per week was found to be higher (10.5 servings) among male nondrinkers than among heavy drinkers (9.0 servings). ${ }^{16}$

Ghana is a low-middle-income country with a noted decline in total alcohol consumption. ${ }^{10}$ However, among drinkers, the volume of consumption remains high with an alcohol per capita of $10 \mathrm{~L}$, especially of locally brewed beverages. This is even considered an underestimation and in 2016 alone, it resulted in 2194 alcoholattributable deaths from cirrhosis. ${ }^{10}$ Separate studies on FnV consumption have often reported levels far below the recommended levels for the majority of the Ghanaian population. ${ }^{5617}$ Ruel et al estimates that FnV consumption is approximately $137.3 \mathrm{~g}$ per day, just about a third of the daily requirement. ${ }^{18}$ Estimates from the 2014 Ghana demographic health survey also show that on average, women in fertile age (15-49 years old) consume FnV on only 3 out of 7 days. ${ }^{19}$ These are likely contributors to the increasing burden of NCDs such as obesity, hypertension and diabetes mellitus in Ghana. ${ }^{20-22}$

The prevalence of these diseases is higher in older adults. These adults are also less likely to have the financial resources to spend on these diseases as they are often past their prime working lives at this time. ${ }^{623}$ It is reasonable to expect these adults to adopt simple and costeffective measures like reducing alcohol consumption and increasing FnV intake to improve their health and reduce their risk of NCD. This will be in line with United Nations Sustainable Development Goals agenda 2030 goal 3 (ensure healthy lives and promote well-being for all at 
Table 2 Adjusted logistic regression showing significant factors associated with alcohol consumption among Ghanaians aged $50+$ years

\begin{tabular}{|c|c|c|c|c|}
\hline \multirow[b]{2}{*}{ Covariate } & \multirow[b]{2}{*}{ aOR } & \multirow[b]{2}{*}{ P-value } & \multicolumn{2}{|l|}{$95 \% \mathrm{Cl}$} \\
\hline & & & Lower & Upper \\
\hline \multicolumn{5}{|l|}{ Sex } \\
\hline Female & Ref & & & \\
\hline Male & 5.09 & 0.000 & 3.58 & 7.24 \\
\hline \multicolumn{5}{|l|}{ Age group, years } \\
\hline $80+$ & Ref & & & \\
\hline $50-59$ & 1.61 & 0.036 & 1.03 & 2.51 \\
\hline $60-69$ & 1.32 & 0.201 & 0.86 & 2.04 \\
\hline $70-79$ & 1.37 & 0.127 & 0.91 & 2.05 \\
\hline \multicolumn{5}{|l|}{ Marital status } \\
\hline Married & Ref & & & \\
\hline Never married & 1.42 & 0.346 & 0.68 & 2.96 \\
\hline Separated & 1.61 & 0.040 & 1.02 & 2.52 \\
\hline Widowed & 1.05 & 0.817 & 0.71 & 1.53 \\
\hline \multicolumn{5}{|l|}{ Religion } \\
\hline Christian & Ref & & & \\
\hline None & 4.10 & 0.000 & 2.08 & 8.09 \\
\hline Islam & 0.15 & 0.000 & 0.09 & 0.25 \\
\hline Primal indigenous & 1.99 & 0.012 & 1.16 & 3.39 \\
\hline \multicolumn{5}{|l|}{ Place of residence } \\
\hline Urban & Ref & & & \\
\hline Rural & 1.42 & 0.010 & 1.09 & 1.84 \\
\hline
\end{tabular}

Region

\begin{tabular}{|lllll}
\hline Northern & Ref & & & \\
\hline Ashanti & 0.70 & 0.393 & 0.31 & 1.57 \\
\hline Brong Ahafo & 0.83 & 0.693 & 0.34 & 2.05 \\
\hline Central & 1.62 & 0.259 & 0.69 & 3.81 \\
\hline Eastern & 1.51 & 0.290 & 0.70 & 3.29 \\
\hline GT. Accra & 1.28 & 0.558 & 0.55 & 2.97 \\
\hline Upper East & 0.65 & 0.422 & 0.23 & 1.84 \\
\hline Upper West & 0.80 & 0.630 & 0.32 & 1.97 \\
\hline Volta & 2.30 & 0.040 & 1.04 & 5.09 \\
\hline Western & 0.96 & 0.920 & 0.44 & 2.11 \\
\hline Ever used tobacco & & & & \\
\hline No & Ref & & & \\
\hline Yes & 3.81 & 0.000 & 2.43 & 5.97 \\
\hline QoL & & & & \\
\hline BMl & & & & \\
\hline Normal & Ref & & & \\
\hline Underweight & 1.23 & 0.312 & 0.82 & 1.85 \\
\hline Overweight & 0.89 & 0.572 & 0.59 & 1.34 \\
\hline Obesity & 1.31 & 0.349 & 0.74 & 2.34 \\
\hline Poor & Ref & & & \\
\hline Low & 1.35 & 0.463 & 0.59 & 3.08 \\
\hline & & & & Continued \\
\hline
\end{tabular}

Table 2 Continued

\begin{tabular}{lllll} 
& & & \multicolumn{2}{c}{$95 \% \mathbf{C l}$} \\
\cline { 4 - 5 } Covariate & aOR & P-value & Lower & Upper \\
\hline Moderate & 1.39 & 0.347 & 0.69 & 2.79 \\
$\quad$ High & 1.82 & 0.139 & 0.82 & 4.06 \\
$\begin{array}{l}\text { Educational level } \\
\text { None }\end{array}$ & & & & \\
Primary & Ref & & & \\
Secondary & 1.35 & 0.087 & 0.96 & 1.89 \\
Tertiary & 1.44 & 0.063 & 0.98 & 2.11 \\
\hline & 1.35 & 0.365 & 0.70 & 2.58 \\
\hline
\end{tabular}

aOR, adjusted Odd Ratio; BMI, body mass index; QoL, quality of life.

all ages.) ${ }^{24}$ To achieve this will also require data to guide policy decisions. While there are separate data on alcohol use and FnV consumption, there is a paucity of literature on the relationship between alcohol and FnV consumption in this high-risk group for NCD from Ghana. The aim of this study, therefore, was to determine the factors associated with alcohol consumption and assess the relationship between alcohol consumption and FnV intake among Ghanaians aged 50 years and older.

\section{Methods}

This study used WHO SAGE Wave 2 Ghana data set conducted between 2014 and 2015. ${ }^{25}$ Data on demographic characteristics, work history and benefits were collected for the study. Also, personal health information for participants including anthropometrics, performance tests, biomarker risk factors and preventive health behaviours (including alcohol, FnV consumption), chronic conditions (self-reported chronic health conditions including hearing difficulty), health services coverage, healthcare utilisation, social networks, subjective well-being and quality of life (QoL), and impact of caregiving were captured in the study. ${ }^{26}{ }^{27}$ The study adopted a complex survey method involving a multistage cluster sampling design of 250 primary sample units and 20 strata with sampling weights for each participant. ${ }^{25}$ Details about the study design and procedures for data collection have been published elsewhere. ${ }^{28}$

\section{Study participants}

SAGE involved two populations; a nationally representative sample of adults aged 50 years and older, and a smaller comparative sample of persons aged 18-49 years. However, our study only analysed data of the older adults aged 50 years and above with a total sample of 3533 participants.

\section{Dependent variables}

Two dependents variables were involved in this study: alcohol consumption and $\mathrm{FnV}$ intake among participants.

With regards to alcohol consumption, participants were asked, 'Have you ever consumed a drink that contains alcohol (such as beer, wine, spirits)?' Those 
Table 3 Sex and place of residence mean daily differential of alcohol consumption among older adults in Ghana

\begin{tabular}{|c|c|c|c|c|c|c|c|c|}
\hline & \multicolumn{4}{|c|}{ Equality of variance: sex } & \multicolumn{4}{|c|}{ Equality of variance: residence } \\
\hline & Male & Female & Difference & F-test ( $P$ value) & Urban & Rural & Difference & F-test (P value) \\
\hline \multicolumn{9}{|l|}{ Day } \\
\hline Tuesday & 1.27 & 0.67 & 0.6 & $26.29(0.000)$ & 0.94 & 1.25 & -0.31 & $5.58(0.019)$ \\
\hline Wednesday & 1.28 & 0.7 & 0.58 & $30.99(0.000)$ & 0.96 & 1.26 & -0.3 & $4.41(0.0370$ \\
\hline Saturday & 1.68 & 0.99 & 0.69 & $24.40(0.000)$ & 1.35 & 1.62 & -0.27 & $2.31(0.131)$ \\
\hline Sunday & 1.44 & 0.86 & 0.58 & $26.39(0.000)$ & 1.09 & 1.45 & -0.36 & $4.66(0.032)$ \\
\hline Total & 9.76 & 5.65 & 4.11 & $32.36(0.000)$ & 7.47 & 9.67 & -2.2 & $-5.07(0.000)$ \\
\hline
\end{tabular}

who answered 'yes' were classified as lifetime consumers. The lifetime consumers were further asked, 'Have you consumed alcohol in the last 30 days?' requiring a yes or no answer. Those who answered 'yes' were classified as current consumers. The current consumers were further asked 'During the past 7 days, how many drinks of any alcoholic beverage did you have each day'. Respondents were shown cards to tell the number of 'standard' drinks they consumed per day from Monday to Sunday. Frequencies of alcohol consumption were accumulated for each day for every participant. An index discrete variable was generated to obtain the total consumption of alcohol in a week. The study further assessed the hazardous nature of alcohol consumption among participants using the index variable generated. The classification comprised nonhazardous drinking (women consuming $\leq 14$ drinks/week and men consuming $\leq 21$ drinks/week) and hazardous drinking (women consuming $>14$ drinks/week and men consuming $>21$ drinks/week). ${ }^{29}$

For FnV intake, participants were asked, 'How many servings of fruit do you eat on a typical day? (this can include a slice or bowl of fresh fruit.)' and 'How many servings of vegetables do you eat on a typical day? (this can include Kontomire leaves, carrots, garden eggs (aubergine/eggplant), cabbage and green beans)'. A composite variable was generated by classifying the variable as a dummy comprising; inadequate $\mathrm{FnV}$ intake (total intake of FnV $<5$ servings/day) coded as one and adequate $\mathrm{FnV}$ intake (total intake of $\mathrm{FnV} \geq 5$ servings/day) coded as 0 .

\section{Independent variables}

Covariates which were analysed in this study included the following; sex, age group (50-59 years, 60-69 years, 70-79 years and $80+$ years), educational level (none, primary, secondary and tertiary), marital status (married, never married, separated/divorced, widowed), religion (none, Christian, Islam and Primal Indigenous), place of residence (rural and urban), region (involving the then 10 administrative regions), history of smoking (yes or no), body mass index (BMI) and QoL (poor, low, moderate and high). BMI was derived from the weight and height measurements using the formula $B M I=\frac{\text { Weight }(\mathrm{kg})}{[\operatorname{Height}(\mathrm{m})]^{2}} \cdot{ }^{30} \mathrm{BMI}$ was then classified as underweight, normal, overweight and obese using the cut-offs $<18.5 \mathrm{~kg} / \mathrm{m}^{2}, 18.5-24.9 \mathrm{~kg} /$ $\mathrm{m}^{2}, 25.0-29.99 \mathrm{~kg} / \mathrm{m}^{2}$ and $>30 \mathrm{~kg} / \mathrm{m}^{2}$ respectively.

\section{Data analysis}

This study adjusted for the primary sampling units, stratification and the individual sampling weights in all the estimates. Rao-Scott $\chi^{2}$ for testing association (for a complex survey) between covariate variables and the outcome variable (alcohol consumption) and equality of mean test statistic to assess the significant mean difference of alcohol consumption weekly by reporting F-test statistic were adopted individually. Multivariate logistic regression was performed to assess significant factors associated with alcohol consumption. Finally, multivariable Poisson, logistic and probit regression analysis were performed to assess the associations between alcohol consumption and inadequate $\mathrm{FnV}$ intake. The models were adopted to estimate log ratio (Poisson estimate), log odds (logistic) and normalised coefficient (probit) to have an in-depth evaluation of the effect of alcohol consumption on inadequate $\mathrm{FnV}$ intake.

\section{Ethical requirements}

Written informed consent was obtained from all study participants.

\section{RESULTS}

\section{Alcohol consumption}

A total of 3533 Ghanaians 50 years and older, $41.0 \%$ men and $59.0 \%$ women, were included in this study. The mean age of the study participants was 62.6 years and mean BMI was $24.2 \mathrm{~kg} / \mathrm{m}^{2}$. The demographic and other characteristics of the study population are shown in table 1 .

The prevalence of lifetime alcohol consumption (history of ever consuming alcohol) was $22.8 \%$. Of these, $93.7 \%$ had consumed alcohol within 7 days and $100 \%$ within 30 days (current drinkers) of the study. Among current drinkers, the prevalence of hazardous drinking was $6.2 \%$ (95\% CI $4.4 \%$ to $8.6 \%$ ) and non-hazardous drinking $93.8 \%$ (95\% CI $91.4 \%$ to $95.6 \%$ ). The prevalence of lifetime alcohol use was significantly $(\mathrm{p}<0.05)$ more in men $(36.6 \%)$, the $50-59$ years 


\begin{tabular}{|c|c|c|c|c|}
\hline \multirow[b]{2}{*}{ Variable } & \multicolumn{2}{|l|}{ Alcohol use } & & \multirow[b]{2}{*}{$\chi^{2}$} \\
\hline & No & Yes & & \\
\hline $\begin{array}{l}\text { Number of } \\
\text { fruit intake }\end{array}$ & & & & $\begin{array}{l}1.15 \\
(0.332)\end{array}$ \\
\hline None & $282(9.0)$ & $86(12.2)$ & $368(9.7)$ & \\
\hline 1 & $680(26.0)$ & $155(21.4)$ & $835(24.9)$ & \\
\hline 2 & $825(31.1)$ & $226(32.6)$ & $1051(31.4)$ & \\
\hline $3-4$ & $641(25.6)$ & $154(25.7)$ & 795 (25.6) & \\
\hline $5+$ & $152(8.4)$ & $31(8.1)$ & $183(8.3)$ & \\
\hline Total & 2580 & 652 & 3232 & \\
\hline Mean (SD) & $2.13(1.67)$ & $2.05(1.65)$ & $2.98(1.11)$ & \\
\hline \multicolumn{3}{|c|}{ Number of vegetable intake } & & $\begin{array}{l}1.44 \\
(0.222)\end{array}$ \\
\hline None & $13(0.4)$ & $6(0.9)$ & $19(0.5)$ & \\
\hline 1 & $524(18.9)$ & $138(19.5)$ & $662(19.1)$ & \\
\hline 2 & $810(30.6)$ & $235(32.0)$ & $1045(30.9)$ & \\
\hline $3-4$ & $848(31.4)$ & $205(33.6)$ & $1053(31.9)$ & \\
\hline $5+$ & 457 (31.4) & $88(14.0)$ & $545(17.6)$ & \\
\hline Total & 2652 & 672 & 3323 & \\
\hline Mean (SD) & $2.96(1.97)$ & $2.77(1.86)$ & $3.47(1.01)$ & \\
\hline
\end{tabular}

group $(24.9 \%)$, the never-married $(30 \%)$, the non-religious $(57.5 \%)$, rural residents $(25.2 \%)$, residence in the Volta Region (38\%), self-reported high QoL (30.9\%) and participants with tertiary education $(33.9 \%)$ than in their other counterparts (table 1).

Logistic regression showed that alcohol consumption was associated with sex, age group, marital status, religion, place of residence and history of ever smoking. The results depict that men were over fivefold more likely to consume alcohol compared with women $(\mathrm{aOR}(95 \% \mathrm{CI})=5.09$ (3.58 to 7.24$))$. Also, the prevalence of alcohol consumption among respondents without religion was over four times more compared with Christians ( $\mathrm{aOR}(95 \% \mathrm{CI})=4.10$ (2.08 to 8.09)) while the practice of Islam significantly decreased the log odds to consume alcohol by 0.15 (aOR $(95 \% \mathrm{CI})=0.15$ ( 0.09 to $0.25)$ ). Rural residents and respondents with a history of ever smoking were also more likely to consume alcohol compared with urban residents and respondents with no history of ever smoking. (aOR $(95 \% \mathrm{CI})=1.42$ (1.09 to 1.84$)$ and 3.81 (2.43 to 5.97)), respectively) (table 2).

The mean daily alcohol consumption was significantly higher on all days of the week for men than women and in rural than in urban areas. Alcohol consumption was also highest for Friday, Saturday and Sunday. The mean total weekly alcohol consumption was 9.76 and 5.65 for men and women, respectively (table 3 ).

\section{FnV intake}

The prevalences of adequate and inadequate daily $\mathrm{FnV}$ intakes were $52.6 \%$ and $47.4 \%$, respectively. The mean daily FnV intake was 6.45 servings: 2.98 for fruits and 3.47 for vegetables. The mean daily FnV intakes for alcohol consumers were 2.05 and 2.77 servings, respectively. Also, $12.2 \%$ and $0.9 \%$ of alcohol consumers ate no daily fruits or vegetables, respectively (table 4).

\section{Relationship between alcohol and FnV consumption}

There was a significant positive correlation between inadequate $\mathrm{FnV}$ intake and lifetime alcohol consumption as presented in table 5. Controlling for significant factors influencing alcohol consumption, using Poisson and logistic regression showed that alcohol consumption was significantly associated with inadequate FnV intake. The analysis shows that inadequate FnV consumption among lifetime alcohol consumers was significantly higher compared with non-alcohol consumers. Inadequate FnV intake as estimated by Poisson and logistic regressions was $35 \%$ and $13 \%$ higher $(\mathrm{aPR}(95 \% \mathrm{CI})=1.35$ (1.12 to 1.63$)$ and $\mathrm{aOR}(95 \% \mathrm{CI})=1.13$ (1.05 to 1.21$)$, respectively) among alcohol consumers compared with non-alcohol consumers. Similarly, the probit model showed that alcohol consumption significantly increased the log odds by 0.19 of inadequate $\mathrm{FnV}$ intake compared with nonalcohol consumption $(\mathrm{a} \beta \quad(95 \%$ CI $)=0.19(0.07-0.31))$ (table 6).

\section{DISCUSSION}

This analysis reports a lifetime alcohol consumption prevalence of 23\% among older adults in Ghana. Interestingly, all lifetime consumers are also current consumers (consumption within the past 30 days). This is quite similar to lifetime alcohol use prevalence of $25.1 \%$ previously reported among secondary school students in Ghana. ${ }^{31}$ This could suggest drinking habits once acquired in adolescence remain unchanged into older adulthood. This is worrying because, it is expected of all individuals especially as they grow, to become more health conscious and modify their lifestyles to have better health. This does not appear to be the case from this study. Fortunately, the hazardous drinking level of $6.2 \%$ among the current drinkers is low.

This analysis further confirms previous reports of gender differences in alcohol consumption with more men than women reporting alcohol use. ${ }^{32}$ However, the prevalence of lifetime alcohol use among the older, adult female population was $10 \%$, lower than the $17.5 \%$ reported among a relatively younger Ghanaian population of 15-49 year olds by Tampah-Naah and Amoah. ${ }^{33}$

Also, alcohol use was higher among the non- religious than the religious. Among the religious, fewer Muslims than Christians and the primal indigenous used alcohol. This is similar to other reports that attending a religious service once a week and religiosity were protective against alcohol use and associated with more restrictive alcohol policies. ${ }^{345}$ The majority Muslim (60\%) community in the Northern Region of Ghana is more likely to have more restrictive alcohol policies accounting for the low prevalence of lifetime alcohol use $(10 \%)$ in the Northern Region. $^{36}$ 
Table 5 Pairwise correlation coefficients between alcohol use, fruit intake, vegetable intake

\begin{tabular}{lc}
\hline Variable & Alcohol use \\
\hline Inadequate fruit and vegetable & $0.04^{\star *}$ \\
Fruit intake & -0.02 \\
Vegetable intake & $-0.045^{\star *}$ \\
\hline
\end{tabular}

P-value notaion: ${ }^{* \star} p$-value $\leq 0.01$

The difference in alcohol consumption patterns between regions of the world and between countries is well documented. ${ }^{1} 1037$ This analysis found differences in consumption patterns within geographical locations (place and region of residence) in Ghana. The observation that rural dwellers consume more alcohol than urban dwellers is similar to reports in the Rodam Study from Ghana and other similar studies. ${ }^{3438}$ The reasons for this most likely include lower cost of alcohol consumed in the rural areas which are mostly locally brewed beverages like 'Akpeteshie', 'Brukutu' and 'Pito' ${ }^{34} 39$ Another reason is the limited availability of alternatives to alcohol for socialisation in rural settings. In Ghana, it is also a truism that cultural and traditional practices are still more elaborately celebrated in rural areas than in many urban settings. These are often strongly linked to alcohol consumption. Thus, overall, rural communities do have a more permissive drinking culture than urban areas. These cultural and traditional practices such as funerals often occur from Fridays to Sundays and these days are associated with more alcohol drinking as demonstrated by this analysis.

The prevalence of alcohol use was relatively higher among older adults with higher perceived QoL. This observation is consistent with the findings of Chan et al who reported that regular alcohol consumption is associated with increased QoL in older men and women. ${ }^{40}$ What is not certain, however, is whether the difference in the QoL was the reason for drinking or the effect. This could not be determined from this study due to the nature of the data used for this analysis.

Another observation from this analysis was that increased prevalence of lifetime alcohol use was associated with an increasing level of education. The demands and stress of higher learning and more socialisation associated with the prolonged stay in institutions of higher learning are possible reasons for this finding. This is, however, contrary to other reports that suggest that alcohol consumption is higher in persons with lower educational attainment. $^{34} 41$ Differences in the amounts of alcohol consumed in the different studies may be the reason for

Table 6 Sensitivity analysis showing the impact of alcohol consumption on inadequate fruit or vegetable fruit per day

\begin{tabular}{|c|c|c|c|}
\hline & Poisson & Logistic & Probit \\
\hline Covariate & aPR (95\% Cl) & aOR $(95 \% \mathrm{Cl})$ & aß $(95 \% \mathrm{Cl})$ \\
\hline \multicolumn{4}{|l|}{ Alcohol consumption } \\
\hline Yes & $1.35(1.12 \text { to } 1.63)^{\star \star *}$ & $1.13(1.05 \text { to } 1.21)^{\star \star *}$ & $0.19(0.07 \text { to } 0.31)^{\star \star}$ \\
\hline \multicolumn{4}{|l|}{ Sex } \\
\hline \multicolumn{4}{|l|}{ Religion } \\
\hline Christian & Ref & Ref & Ref \\
\hline None & 0.78 (0.53 to 1.15$)$ & 0.91 (0.77 to 1.06$)$ & $-0.15(-0.39$ to 0.09$)$ \\
\hline Islam & $0.80(0.66 \text { to } 0.97)^{\star}$ & $0.91(0.84 \text { to } 0.99)^{\star}$ & $-0.14(-0.25 \text { to }-0.02)^{*}$ \\
\hline \multicolumn{4}{|l|}{ Place of residence } \\
\hline Rural & 0.96 (0.83 to 1.12$)$ & 0.98 (0.93 to 1.04$)$ & $-0.02(-0.11$ to 0.07$)$ \\
\hline No & Ref & & \\
\hline Yes & 1.08 (0.81 to 1.43$)$ & 1.03 (0.92 to 1.15$)$ & $0.05(-0.13$ to 0.22$)$ \\
\hline \multicolumn{4}{|l|}{ Educational level } \\
\hline None & Ref & Ref & Ref \\
\hline Primary & 0.87 (0.73 to 1.04$)$ & 0.95 (0.88 to 1.02$)$ & $-0.08(-0.19$ to 0.03$)$ \\
\hline Secondary & 0.89 (0.74 to 1.08$)$ & 0.96 (0.89 to 1.03$)$ & $-0.07(-0.19$ to 0.05$)$ \\
\hline Tertiary & 0.97 (0.65 to 1.44$)$ & 0.99 (0.84 to 1.15$)$ & $-0.02(-0.27$ to 0.22$)$ \\
\hline
\end{tabular}

${ }^{*} \mathrm{p} \leq 0.05 ;{ }^{* *} \mathrm{p} \leq 0.01 ;{ }^{* * *} \mathrm{p} \leq 0.001$.

a $\beta$, adjusted normalized coefficient; aOR, adjusted Odd Ratio; aPR, adjusted Prevalence Ratio. 
our contradictory findings. Hazardous drinking is more prevalent in persons with lower education, but this study did not determine the relationship between amount of alcohol consumed and level of education.

Overall, FnV consumption is essential to the health of individuals especially among older adults and was key in this analysis. Even though the mean FnV serving is higher than recommended by experts and the previous estimates by Ruel $e t$ al among Ghanaians, nearly half $(47.4 \%)$ of the study population did not consume adequate $\mathrm{FnV}^{2}{ }^{18}$ This finding of inadequate $\mathrm{FnV}$ intake agrees with that found among older adults in China. ${ }^{8}$ The prevalence of inadequate FnV intake among older adults in Ghana reported in this study is better than the prevalence of $68.9 \%$ reported in SAGE Wave 1 and also relatively better than previous estimates from other Sub-Saharan African countries; $68 \%$ in South Africa, $73 \%$ in Nigeria, $87.8 \%$ in Uganda and $94 \%$ in Kenya. ${ }^{612}{ }^{12-45}$ It is also lower than the previously reported global mean prevalence of inadequate $\mathrm{FnV}$ of $77.6 \%$ for men and $78.4 \%$ for women but higher than the means for Ghanaian men and women $(36.8 \%$ and $38 \%$, respectively) in a study of 52 low-income middleincome countries. ${ }^{5}$ Availability may likely play a role in these differences, but further studies will be required to identify the true reasons for these wide differences.

This study also concurs with previous reports that alcohol consumption impairs FnV intake. ${ }^{14-16}$ In a study among elderly Chinese between 1991 and 2009, despite an increase in $\mathrm{FnV}$ intake, a significant association between alcohol drinking and inadequate FnV intake was maintained. ${ }^{46}$ This potentially could be due to the tendency for the clustering of harmful lifestyles including alcohol consumption, smoking, physical inactivity and poor diet. Persons who consume alcohol tend to have concomitant risky health behaviours including low FnV intake. ${ }^{47}$ Additionally, alcohol contributes to the daily calorie requirement of its consumers and therefore is likely to lower their intake of other foods including FnV. However, the negative influence of alcohol use on FnV intake has not been consistently reported in all studies. In a study among older adults in South Africa, alcohol use did not have any effect on FnV intake. ${ }^{42}$ Other studies have also reported increased FnV intake with consumption of some alcoholic beverages such as wine but not others. ${ }^{48}$ It will be interesting to explore the relationship between the amount and type of alcohol consumed and the influence on the FnV intake among the older, adult population in Ghana.

The findings and interpretations from this study must be viewed with consideration for some limitations. Alcohol consumption and FnV intake were subjectively assessed (were self-reported) and therefore could have been affected by recall bias and local social, cultural and religious nuances, and permissiveness and acceptability of certain behaviours. This has however been used in many population-based studies and found to be reliable. Also, the cross-sectional nature of the SAGE Wave 2 Study did not allow evaluation of changes in alcohol consumption and FnV intake over time. Longitudinal studies will be needed to study these changes. The release of SAGE Wave 3 will allow such a longitudinal study.

\section{CONCLUSIONS}

About one out of five older Ghanaian adults are current alcohol consumers. The prevalence of alcohol consumption among older Ghanaian adults is like that of the younger population. Nearly half of the older, adult population consumes inadequate FnV. Alcohol consumption is significantly associated with inadequate FnV intake. Interventions to address inadequate $\mathrm{FnV}$ intake among older adults in Ghana should include policies that address factors that influence the use of alcohol in this target population.

Acknowledgements The authors thank all respondents and interviewers who made the SAGE, Wave 2 Survey in Ghana possible. The authors also thank WHO for contributing financial and human resources to SAGE- 2; the Ministry of Health, Ghana, for supporting SAGE 2; the University of Ghana's Department of Community Health for contributing training facilities, data entry support and storage of materials; and the Ghana Statistical Office for providing the sampling information for the sampling frame and updates.

Contributors KT and AEY developed the concept. KT, JT and AEY were involved in the data analysis and drafting of the results. KT, AEY, AA-N and TA contributed to the writing and reviewing of the manuscript. All authors read and approved the final manuscript.

Funding The authors have not declared a specific grant for this research from any funding agency in the public, commercial or not-for-profit sectors.

Competing interests No, there are no competing interests.

Patient consent for publication Not required.

Ethics approval The SAGE Wave 2 study was approved by WHO's Ethical Review Board with reference number RPC149 and, the Ethical and Protocol Review Committee, College of Health Sciences, University of Ghana, Accra, Ghana.

Provenance and peer review Not commissioned; externally peer reviewed.

Data availability statement Data are available in a public, open access repository. The minimal data set used to support the findings of this study is available upon request through the WHO website http://www.who.int/healthinfo/sage/cohorts/en/.

Open access This is an open access article distributed in accordance with the Creative Commons Attribution Non Commercial (CC BY-NC 4.0) license, which permits others to distribute, remix, adapt, build upon this work non-commercially, and license their derivative works on different terms, provided the original work is properly cited, appropriate credit is given, any changes made indicated, and the use is non-commercial. See: http://creativecommons.org/licenses/by-nc/4.0/.

\section{REFERENCES}

1 Lim SS, Vos T, Flaxman AD, et al. A comparative risk assessment of burden of disease and injury attributable to 67 risk factors and risk factor clusters in 21 regions, 1990-2010: a systematic analysis for the global burden of disease study 2010. Lancet 2012;380:2224-60.

2 World Health Organization. Diet, nutrition, and the prevalence of chronic diseases. 916. Geneva, Switzerland: World Health Organization; WHO Technical Report Series, 2003.

3 He FJ, Nowson CA, Lucas M, et al. Increased consumption of fruit and vegetables is related to a reduced risk of coronary heart disease: meta-analysis of cohort studies. J Hum Hypertens 2007;21:717-28.

4 Lock K, Pomerleau J, Causer L, et al. The global burden of disease attributable to low consumption of fruit and vegetables: implications for the global strategy on diet. Bull World Health Organ 2005;83:100-8.

5 Hall JN, Moore S, Harper SB, et al. Global variability in fruit and vegetable consumption. Am J Prev Med 2009 ;;36:402-9.

6 Wu F, Guo Y, Chatterji S, et al. Common risk factors for chronic non-communicable diseases among older adults in China, Ghana, 
Mexico, India, Russia and South Africa: the study on global ageing and adult health (SAGE) wave 1. BMC Public Health 2015;15:88.

7 Franchini B, Poínhos R, Klepp K-I, et al. Fruit and vegetables: intake and sociodemographic determinants among Portuguese mothers. Ann Nutr Metab 2013;63:131-8.

8 Li YC, Jiang B, Zhang M, et al. Vegetable and fruit consumption among Chinese adults and associated factors: a nationally representative study of 170,847 adults. Biomed Environ Sci 2017;30:863-74.

9 Herbeth B, Samara A, Stathopoulou M, et al. Alcohol consumption, beverage preference, and diet in middle-aged men from the STANISLAS study. J Nutr Metab 2012;2012:1-6.

10 World Health Organization. Substabce abuse: global status report on alcohol and health 2018

11 Shield KD, Parry C, Rehm J. Chronic diseases and conditions related to alcohol use. Alcohol Res 2013;35:155-73.

12 Zhou Y, Zheng J, Li S, et al. Alcoholic beverage consumption and chronic diseases. Int J Environ Res Public Health 2016;13:522.

13 Shimotsu ST, Jones-Webb RJ, Lytle LA, et al. The relationships among socioeconomic status, fruit and vegetable intake, and alcohol consumption. Am J Health Promot 2012;27:21-8.

14 Pengpid S, Vonglokham M, Kounnavong S, et al. The prevalence and social determinants of fruit and vegetable consumption and its associations with noncommunicable diseases risk factors among adults in Laos. Asia Pac J Public Health 2019;31:157-66.

15 Kesse E, Clavel-Chapelon F, Slimani N, et al. Do eating habits differ according to alcohol consumption? results of a study of the French cohort of the European prospective investigation into cancer and nutrition (E3N-EPIC). Am J Clin Nutr 2001;74:322-7.

16 La Vecchia C, Negri E, Franceschi S, et al. Differences in dietary intake with smoking, alcohol, and education. Nutr Cancer 1992;17:297-304

17 Ghose B, Yaya S. Fruit and vegetable consumption and anemia among adult non-pregnant women: Ghana demographic and health survey. PeerJ 2018;6:e4414.

18 Ruel MT, Minot N, Smith L. Patterns and determinants of fruit and vegetable consumption in sub-Saharan Africa: a multicountry comparison: who Geneva 2005.

19 Ghana Statistical Service, (GSS), Ghana Health Service, (GHS), International I. Ghana demographic and health survey 2014 Rockville, Maryland, USA: GSS, GHS, and ICF International, 2015.

20 Abubakari AR, Bhopal RS. Systematic review on the prevalence of diabetes, overweight/obesity and physical inactivity in Ghanaians and Nigerians. Public Health 2008;122:173-82.

21 Dosoo DK, Nyame S, Enuameh Y, et al. Prevalence of hypertension in the middle belt of Ghana: a community-based screening study. Int $J$ Hypertens 2019;2019:1-7.

22 de-Graft Aikins A, Addo J, Ofei F, et al. Ghana's burden of chronic non-communicable diseases: future directions in research, practice and policy. Ghana Med J 2012;46:1-3.

23 Tagoe HA. Household burden of chronic diseases in Ghana. Ghana Med J 2012;46:54-8.

24 Colglazier W. Sustainability. sustainable development agenda: 2030. Science 2015;349:1048-50.

25 Who study on global ageing and adult health (SAGE), health statistics and information systems, 2015. Available: http://www.who.int/ healthinfo/sage/en/ [Accessed 29 May 2019].

26 Agrawal G, Patel SK, Agarwal AK. Lifestyle health risk factors and multiple non-communicable diseases among the adult population in India: a cross-sectional study. J Public Health 2016;24:317-24.

27 Minicuci N, Biritwum RB, Mensah G, et al. Sociodemographic and socioeconomic patterns of chronic non-communicable disease among the older adult population in Ghana. Glob Health Action 2014;7:21292.

28 Kowal P, Chatterji S, Naidoo N, et al. Data resource profile: the world Health organization study on global ageing and adult health (SAGE). Journal of Public Health 2012;41:1639-49.
29 Saunders JB, Aasland OG, Babor TF, et al. Development of the Alcohol Use Disorders Identification Test (AUDIT): WHO Collaborative Project on Early Detection of Persons with Harmful Alcohol Consumption--II. Addiction 1993;88:791-804.

30 Blackburn H, Jacobs D. Commentary: origins and evolution of body mass index (BMI): continuing SAGA. Int J Epidemiol 2014:43:665-9.

31 Osei-Bonsu E. Prevalence of alcohol consumption and factors influencing alcohol use among the youth in Tokorni-Hohoe, Volta region of Ghana. SJPH 2017;5:205-14.

32 Erol A, Karpyak VM. Sex and gender-related differences in alcohol use and its consequences: contemporary knowledge and future research considerations. Drug Alcohol Depend 2015;156:1-13.

33 Tampah-Naah AM, Amoah ST. Consumption and drinking frequency of alcoholic beverage among women in Ghana: a cross-sectional study. BMC Public Health 2015;15:317.

34 Addo J, Cook S, Galbete C, et al. Differences in alcohol consumption and drinking patterns in Ghanaians in Europe and Africa: the RODAM study. PLoS One 2018;13:e0206286.

35 Michalak L, Trocki K, Bond J. Religion and alcohol in the U.S. national alcohol survey: how important is religion for abstention and drinking? Drug Alcohol Depend 2007;87:268-80.

36 Ghana Statistical Service. 2010 population and housing census report: Ghana statistical service 2014

37 Shield KD, Rylett M, Gmel G, et al. Global alcohol exposure estimates by country, territory and region for 2005--a contribution to the Comparative Risk Assessment for the 2010 Global Burden of Disease Study. Addiction 2013;108:912-22.

38 Oyebode O, Pape UJ, Laverty AA, et al. Rural, urban and migrant differences in non-communicable disease risk-factors in middle income countries: a cross-sectional study of WHO-SAGE data. PLOS One 2015;10:e0122747.

39 Luginaah I, Dakubo C. Consumption and impacts of local brewed alcohol (akpeteshie) in the upper West region of Ghana: a public health tragedy. Soc Sci Med $2003 ; ; 57: 1747-60$.

40 Chan AM, von Mühlen D, Kritz-Silverstein D, et al. Regular alcohol consumption is associated with increasing quality of life and mood in older men and women: the Rancho bernardo study. Maturitas 2009;62:294-300.

41 Droomers M, Schrijvers CT, Stronks K, et al. Educational differences in excessive alcohol consumption: the role of psychosocial and material stressors. Prev Med 1999;29:1-10.

42 Peltzer K, Phaswana-Mafuya N. Fruit and vegetable intake and associated factors in older adults in South Africa. Glob Health Action 2012:5:18668-8.

43 Olatona FA, Sosanya A, Sholeye OO, et al. Knowledge of fruits and vegetables, consumption pattern and associated factors among adults in Lagos state, Nigeria. Research Journal of Health Sciences 2018;6:50-62.

44 Kabwama SN, Bahendeka SK, Wesonga R, et al. Low consumption of fruits and vegetables among adults in Uganda: findings from a countrywide cross-sectional survey. Arch Public Health 2019;77:4.

45 Pengpid S, Peltzer K. The prevalence and social determinants of fruit and vegetable consumption among adults in Kenya: a crosssectional national population-based survey, 2015. Pan Afr Med J 2018:31:137

$46 \mathrm{Li} \mathrm{Y,} \mathrm{Li} \mathrm{D,} \mathrm{Ma} \mathrm{C-yuan,} \mathrm{et} \mathrm{al.} \mathrm{Consumption} \mathrm{of,} \mathrm{and} \mathrm{factors} \mathrm{influencing}$ consumption of, fruit and vegetables among elderly Chinese people. Nutrition 2012;28:504-8.

47 Ma J, Betts NM, Hampl JS. Clustering of lifestyle behaviors: the relationship between cigarette smoking, alcohol consumption, and dietary intake. Am J Health Promot 2000;15:107-17.

48 Barefoot JC, Grønbaek M, Feaganes JR, et al. Alcoholic beverage preference, diet, and health habits in the unc alumni heart study. Am $J$ Clin Nutr 2002;76:466-72. 